\title{
A simple and rapid method for assessing similarities among directly observable behavioral effects of drugs: PCP-like effects of 2-amino-5-phosphonovalerate in rats
}

\author{
W. Koek ${ }^{1}$, J.H. Woods ${ }^{1,2}$, and P. Ornstein ${ }^{3}$ \\ ${ }^{1}$ Department of Pharmacology and ${ }^{2}$ Department of Psychology, M6322 Medical Science Building I, \\ University of Michigan, Ann Arbor, MI 48109-0010, USA \\ ${ }^{3}$ Lilly Research Laboratories, McCarty St., Indianapolis, IN 46285, USA
}

\begin{abstract}
Directly observable behavioral effects of the Nmethyl-D-aspartate (NMDA) receptor antagonist 2-amino5-phosphonovalerate (AP5) $\quad(10-1,000 \mathrm{mg} / \mathrm{kg} \quad$ IP, $0.18-$ $5.6 \mu \mathrm{mol} / \mathrm{rat} \mathrm{ICV})$ and of phencyclidine (PCP) $(3.2-56 \mathrm{mg} / \mathrm{kg}$ IP, $0.032-3.2 \mathrm{mg} / \mathrm{rat}$ ICV), ketamine $(10-100 \mathrm{mg} / \mathrm{kg})$, amphetamine $(1-18 \mathrm{mg} / \mathrm{kg})$, apomorphine $(0.1-5.6 \mathrm{mg} / \mathrm{kg})$, chlordiazépoxide $(1-100 \mathrm{mg} / \mathrm{kg})$, and pentobarbital (3.2$56 \mathrm{mg} / \mathrm{kg}$ ) were studied in rats. Pharmacologically specific results were obtained rapidly and reliably, using a cumulative dosing procedure. Cluster analysis grouped the drug treatments, on the basis of their similarities in producing different behavioral activities, into three main clusters; characteristically, stimulant drugs (amphetamine, apomorphine) produced sniffing and gnawing; PCP-like drugs (PCP, ketamine) produced locomotion, sniffing, swaying and falling; sedative drugs (pentobarbital, chlordiazepoxide) produced loss of righting. The behavioral effects of ICV administration of AP5 were more similar to the effects of PCP-like drugs than to the effects of either stimulant or sedative drugs, thus supporting the hypothesis that the behavioral effects of PCP-like drugs may result from reduced neurotransmission at excitatory synapses utilizing NMDA preferring receptors. The present procedure is simple, rapid and may provide a useful approach in the classification of behaviorally active drugs.
\end{abstract}

Key words: 2-Amino-5-phosphonovalerate (AP5) - Excitatory amino acid antagonists - Phencyclidine - Ketamine

- Amphetamine - Apomorphine - Pentobarbital - Chlordiazepoxide - Directly observable behaviors - Cumulative dosing - Cluster analysis - Classification - Rats

Recently, we reported that DL-2-amino-5-phosphonovalerate (AP5), a potent and highly selective NMDA antagonist (Watkins and Evans 1981), produces PCP-like catalepsy, discriminative stimulus effects and stereotyped operant responding in pigeons (Koek et al. 1986a, b). In addition, we observed that the ability of NMDA antagonists to induce PCP-like catalepsy is correlated strongly with their relative potency as NMDA antagonists (Mudar et al. 1986). Together, these findings suggest that behavioral effects of PCP-like drugs in pigeons may be mediated by inhibition of neurotransmission at synapses utilizing NMDA receptors. The present study sought to examine whether behav-

Offprint requests to: W. Koek ioral effects of PCP-like drugs in rats may be mediated in a similar fashion.

In rats, $\mathrm{PCP}$ induces locomotor activity, stereotypy and ataxia. These behavioral effects of PCP have been quantified previously by means of rating scales (e.g., Sturgeon et al. 1979). Quantitative rating scales to evaluate the intensity of stereotypy have a number of disadvantages (Fray et al. 1980; Robbins 1977). Most important, they may confound the measurement of stereotypy, which is a description of the nature of behavior, with identification of specific responses. Further, the use of a quantitative rating scale to evaluate PCP-induced behavioral effects in rats appears to be complicated by the failure to observe consistently some of the behavioral activities included in this scale (e.g., backpeddling, "praying"; Greenberg and Segal 1986). A novel observational method for measuring behavioral effects of dopamine agonists, based on direct observation of the occurrence of a number of different behaviors, has been described (Fray etal. 1980) and has been shown to be useful in assessing the behavioral effects of PCP in rats (Iwamoto 1984). An adaptation of this method, that appears to be less complex than a rating-scale approach, was used in the present study.

The first aim of the present study was to investigate directly observable effects of PCP in rats using the method developed by Fray et al. and using a cumulative-dosing procedure that allows the assessment of a dose-response curve for each behavior during a single experimental session (e.g., Thompson and Boren 1977). In addition, drugs that, to varying degrees, may share directly observable behavioral effects with PCP were studied to investigate whether the method used in the present experiment could discriminate reliably between effects induced by PCP-like and non PCPlike drugs. Second, the behavioral effects of the NMDAantagonist AP5 were compared to the effects of the PCP-like and non-PCP-like drugs tested, to evaluate the hypothesis that NMDA antagonism underlies the behavioral activity of PCP in rats. Cluster analysis (e.g., Aldenderfer and Blashfield 1984) was used to find subgroups of the drug treatments that were relatively similar with respect to their directly observable behavioral effects and to investigate the possible assignment of AP5 to a particular subgroup. The generality of the results of the cluster analysis was explored across different similarity measures; the replicability was evaluated by dividing the data set into two replicates, and performing the same method of cluster analysis independently on each half. 


\section{Materials and methods}

Subjects. Male albino rats of the Sprague-Dawley strain (Harlan Industries, Indianapolis, IN) weighing $150-200 \mathrm{~g}$ at the start of the experiment, were housed individually under a 12-h light/dark cycle (lights on at 7 a.m.) and were given free access to food and water. In some of the rats, a chronic, indwelling guide cannula was implanted under anesthesia with the tip directly into the lateral ventricle.

Apparatus. To assess drug-induced behaviors, four perspex cages $(25 \times 30 \times 30 \mathrm{~cm}$ high) with a clear front wall and with a floor consisting of metal bars $(0.3 \mathrm{~cm}$ diameter separated by $1.0 \mathrm{~cm}$ gaps), were used.

Procedure. During experimental sessions, that were conducted during the light portion of the light/dark cycle, four rats were removed from the home cages, and placed singly in an observation cage for a 60 -min habituation period. Then, each rat was sequentially observed for $30 \mathrm{~s}$ and the occurrence of any of the behaviors listed in Table 1 was recorded, with the exception of loss of righting and anesthesia. The behaviors scored were a composite of those from previous studies and our preliminary observations; they were the behavioral categories described by Fray et al. (1980), "fall" was added as described by Iwamoto (1984), and loss of righting, anesthesia and Straub tail were also noted. A rat was scored for any number of the behaviors listed in Table 1, tested for the occurrence of loss of righting and anesthesia, injected, and immediately returned to the observation cage. Injections were given IP $(0.3-1 \mathrm{ml} / \mathrm{rat})$ or ICV $(5 \mu \mathrm{l} / \mathrm{rat})$ at $15-\mathrm{min}$ intervals and behavioral effects were assessed 13-15 min after each injection by an observer who had no knowledge of the treatment received by the rats. Each injected dose (after the first) was calculated such that the total amount injected before each test was $1 / 4-1 / 2$ log-unit greater than the dose of the previous test.

First, amphetamine $(1-18 \mathrm{mg} / \mathrm{kg})$, PCP $(3.2-56 \mathrm{mg} / \mathrm{kg})$, and pentobarbital $(3.2-56 \mathrm{mg} / \mathrm{kg})$ were tested in a cumulative-dosing procedure using four rats per drug (groups 1, 2 and 3, respectively). Two observers (R.C. and M.D.) assessed independently the occurrence of the different behaviors. The effects of six injections of saline at 15-min intervals were assessed by the observers in eight rats (group 4).

Thereafter, four rats (group 5) were tested with $d$-amphetamine $(1-18 \mathrm{mg} / \mathrm{kg})$, chlordiazepoxide $(1-100 \mathrm{mg} / \mathrm{kg})$, pentobarbital $(3.2-56 \mathrm{mg} / \mathrm{kg})$, PCP $(3.2-56 \mathrm{mg} / \mathrm{kg})$, ketamine $(10-100 \mathrm{mg} / \mathrm{kg})$, multiple saline injections, and apomorphine $(0.1-5.6 \mathrm{mg} / \mathrm{kg})$, in that order; in four other rats (group 6), these conditions were tested in the reverse order. An additional group of eight rats (group 7) was used to study the effects of IP administration of AP $5(10-100 \mathrm{mg} / \mathrm{kg}$ and $100-1,000 \mathrm{mg} / \mathrm{kg}$, each tested in four rats). PCP $(0.032-$ $0.56 \mathrm{mg})$, AP5 $(0.18-1.0 \mu \mathrm{mol}$; i.e., $0.042-0.23 \mathrm{mg})$ and four injections of sterile water at 15 -min intervals were tested ICV, in that order in four rats (group 8); three rats (group 9) received these treatments in the reverse order. Further, multiple injections of sterile water and higher ICV doses of PCP $(0.56-3.2 \mathrm{mg})$ and of AP5 $(1.8-5.6 \mu \mathrm{mol})$ were tested in different groups of rats (groups 10,11, and 12) that were drug-naive $(n=8,4$, and 4 , respectively). The $\mathrm{pH}$ of the solutions that were administered ICV ranged from 6 to 7 . Behavioral assessments were made by R.C. Test sessions were separated by at least $48 \mathrm{~h}$.
Data analysis. The reliability of the behavioral assessments was measured by calculating Cohen's kappa (Leach 1979), for each of the behaviors induced by amphetamine, PCP and pentobarbital, using the observations by R.C. and by M.D. Kappa is directly interpretable as the proportion of joint observations in which there is agreement, after chance agreement is excluded; kappa attains a value of 1.0 if there is perfect agreement between the two observers; a value of zero indicates chance agreement and a value of -1.0 indicates complete disagreement. For each drug and each behavior, a $2 \times 2$ contingency table was constructed with the frequencies of the following events as cell entries: 1) behavior present according to both observers, 2) behavior present according to observer R.C. and absent according to observer M.D., 3) behavior absent according to R.C. and present according to M.D., and 4) behavior absent according to both observers. Kappa was calculated using the formula:

$\left(n D-\sum t_{i} u_{i}\right) /\left(n^{2}-\sum t_{i} u_{i}\right)$

where $n$ is the total number of observations, $D$ is the sum of the frequencies of the diagonal cells (i.e., cells 1 and 4), and $t_{i}$ and $u_{i}$ are the row and column marginal totals converging on each diagonal cell. For example, in the test of the effects of seven dose levels of $d$-amphetamine on locomotor activity in four rats (see Fig. 1) there were 15 occasions on which both observers marked the occurrence of locomotor activity, two occasions on which the response was marked by R.C. but not by M.D., one occasion on which locomotion was marked by M.D. but not by R.C., and ten occasions on which locomotion was not marked by both observers, resulting in a value for kappa of 0.78 .

To assess the statistical significance of drug-induced changes in the occurrence of each of the responses listed in Table 1 , data were arranged in $2 \times 2$ contingency tables in the following way. For each dose, the number of rats showing, as well as those not showing a particular response was tabulated. Control values consisted of the number of rats showing, as well as those not showing this response at the corresponding saline injection (i.e., the effects of the first dose of a particular drug were compared with the effects of the first saline injection, etc.). For example, the effects of $1.8 \mathrm{mg} / \mathrm{kg} d$-amphetamine on locomotor activity (see Fig. 1) were analyzed by constructing a $2 \times 2$ contingency table with the following cell entries: 0 (number of rats that did not show locomotion when given drug), 4 (number of rats that showed locomotion when given drug), 6 (number of rats that did not show locomotion after the second saline injection), and 2 (number of rats that showed locomotion after the second saline injection). The degree of heterogeneity in each contingency table was calculated by means of Kullback's information statistic I (Kullback 1968; Robbins 1977), analogous to Chi-square, but not constrained by small cell frequencies. I is defined as:

$\sum n_{i j} \ln n_{i j}-\sum n_{i .} \ln n_{i .}-\sum n_{. j} \ln n_{. j}+N \ln N$

where $n_{i j}$ is the observed frequency in row $i$ and column $j, n_{i}$, and $n_{. j}$ are marginal totals and $N$ is the grand total. 2I is distributed as Chi-square with one degree of freedom for a $2 \times 2$ contingency table. The value of $2 I$ in the aforementioned example is $2 \times(0+4 \ln 4+6 \ln 6+2 \ln 2-4 \ln 4-$ $8 \ln 8-6 \ln 6-6 \ln 6+12 \ln 12)=7.64$, a value of Chi-square with 1 degree of freedom that is significant at the $1 \%$ level. 
d-amphetamine
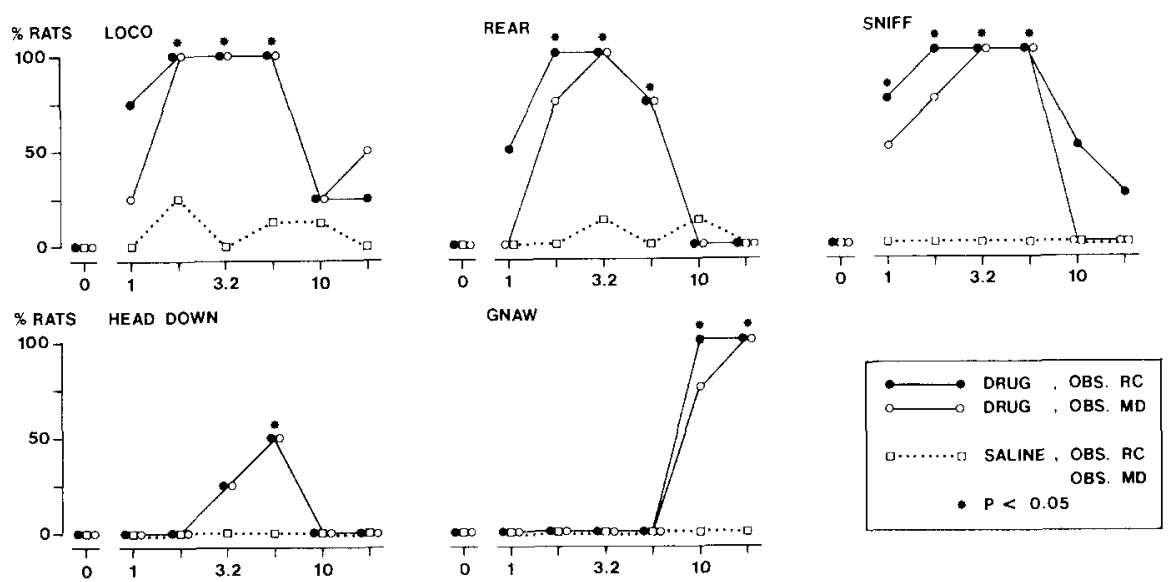

\section{phencyclidine}

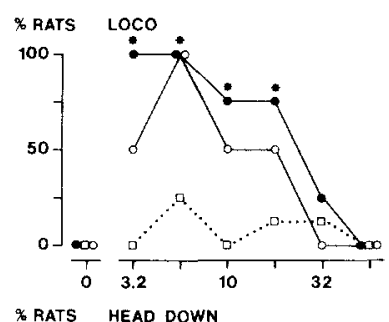

\% RATS HEAD DOWN

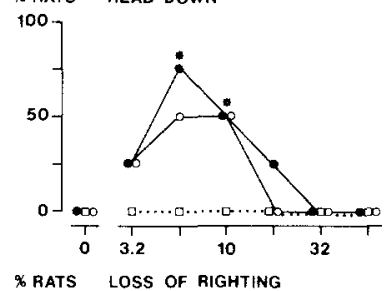

\% RATS LOSS OF RIGHTING
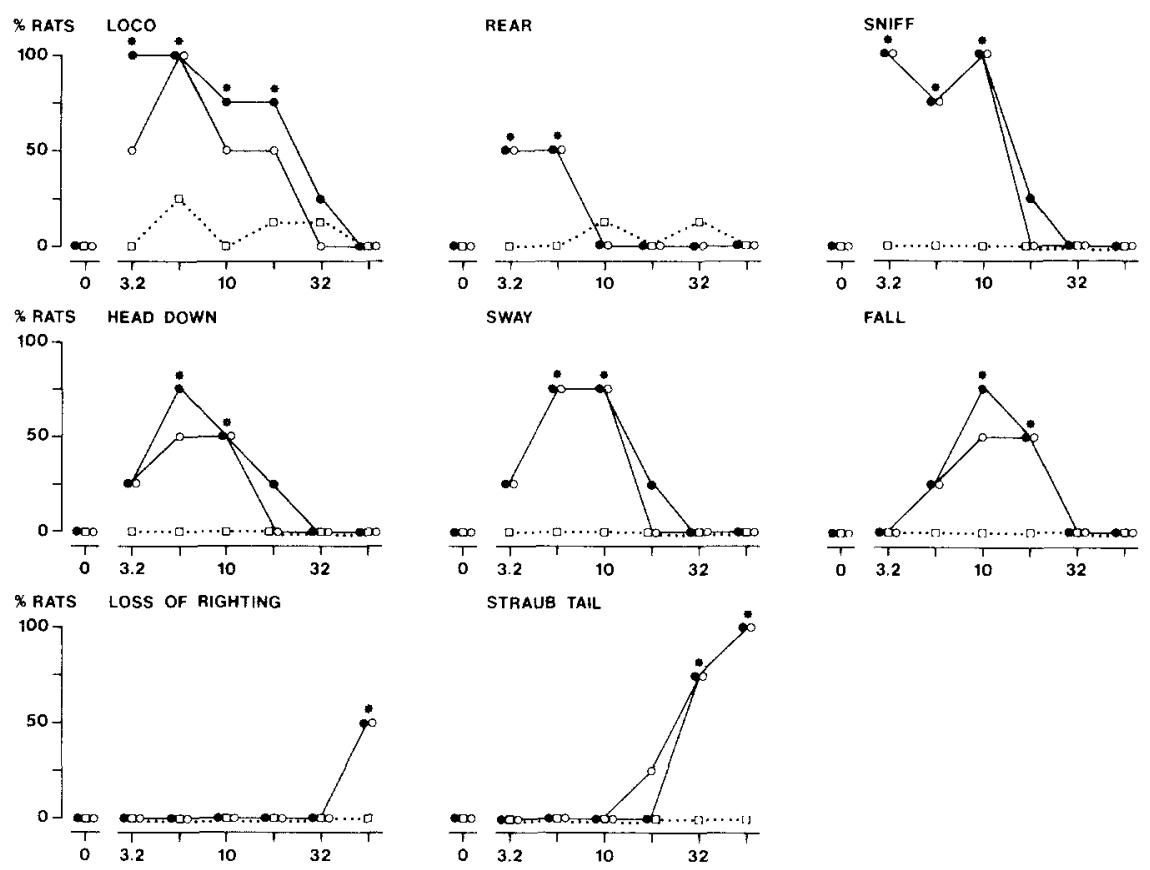

Fig. 1. Directly observable behavioral effects induced, in four rats per drug, by cumulative doses of $d$-amphetamine (upper panels), phencyclidine (middle panels) and pentobarbital (lower panels). Behavioral assessments were made by two independent observers who were blind to the treatment condition. Effects were marked with an asterisk when the assessments of both observers were signficiantly different $(\alpha=0.05)$ from the results obtained in a different group of eight rats during a test of repeated IP injections of saline at $15-\mathrm{min}$ intervals. Drug effects on the activities listed in Table 1 that were not statistically significant are not shown. Ordinates: percentage of rats showing a particular activity, as defined in Table 1; abscissae: cumulative IP dose administered, in $\mathrm{mg} / \mathrm{kg}$
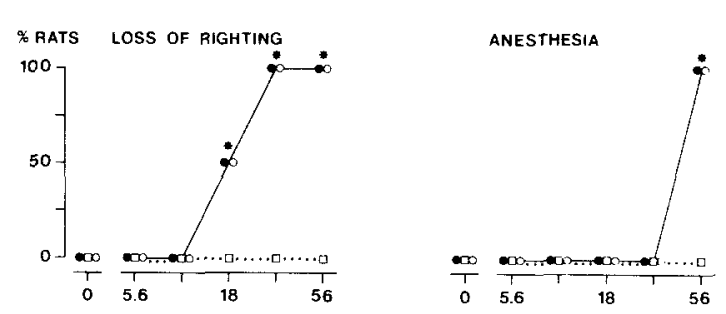

DOSE, MG/KG

For each drug and each behavioral category, the maximum percentage of rats showing the response was determined. The statistical significance of differences of this measure between groups that received drug treatments in an opposite order was assessed by tabulating, for each drug and each group, the number of rats showing, as well as the remaining number of rats not showing a particular response. The resulting contingency table was analyzed by means of Kullback's I statistic. For example, the maximum percentage of rats that showed PCP-induced swaying was 75 in group $5(n=4)$ and was 100 in group $6(n=4)$. These maxima were observed at a dose of $5.6 \mathrm{mg} / \mathrm{kg} \mathrm{PCP}$, in both groups. The entries of the contingency table were: 3 (number of rats in group 5 that showed swaying), 1 (number of rats in group 5 that did not show swaying), 4 (number of rats in group 6 that showed swaying), and 0 (number of rats 
in group 6 that did not show swaying), resulting in a nonsignificant value of Chi-square (i.e., $2 \mathrm{I}=1.53$, one degree of freedom, $p>0.20$ ).

Similarities between drugs with respect to the extent to which they affected each of the responses were quantified by means of Gower's similarity coefficient for quantitative variables (Gordon 1981), which can take on values between 1 (perfect similarity) and 0 (no similarity). Gower's coefficient $s_{i j}$ is defined as:

$$
\sum_{k=1}^{p} w_{i j k} s_{i j k} / \sum_{k=1}^{p} w_{i j k}
$$

In this formula, $s_{i j k}$ is the similarity between the $i$ th and the $j$ th object as measured by the $k$ th variable, and $w_{i j k}$ is 1 or 0 depending on whether or not the comparison is valid for the $k$ th variable. For quantitative variables, $w_{i j k}$ is set equal to 0 only when variable $k$ is unknown for one or both objects; $s_{i j k}$ is defined as $1-\left|x_{i k}-x_{j k}\right| / R_{k}$. In the context of the present study, $w_{i j k}$ was set equal to one in all cases, because there were no missing data; $x_{i k}-x_{j k}$ is the difference between the maximum percentage of rats showing response $k$ after drug $i$ and the maximum percentage of rats showing response $k$ after drug $j ; R_{k}$ is the range of maximum percentage values of response $k$ in the sample of drug treatments and $p$ is the number of response categories $(p=12$ in the present study). For example, the similarity between the effects on locomotor activity of IP and ICV administration of PCP (see Table 2) was calculated as 1$(100-86) /(100-13)=0.84$. The overall similarity of the effects of IP and ICV administration of PCP was obtained by averaging across all 12 response categories. A similarity coefficient was calculated for every pair of drug treatments. To facilitate visual inspection of the similarities between the drug treatments, the resulting matrix was used to construct a tree-diagram in which drug treatments are sequentially joined on the basis of their relative similarities (hierarchical agglomerative cluster analysis; Gordon 1981). Drug treatments are joined at different similarity values as follows: at each stage, the most similar pair is amalgamated, then the similarity between this new group and the remaining groups is calculated as the average similarity between each of the members of the new group and the remaining groups (average linkage method). The most similar pair in the resulting matrix is joined and a new matrix is calculated. The process stops when all drug treatment groups are linked together.

To study the generality across different similarity measures, the cluster analysis was performed also using the simple matching coefficient and Jaccard's coefficient (Gordon 1981). Both coefficients are used as measures of the degree of similarity between cases described by binary variables. In the context of the present study, the matching coefficient between two drug treatments was defined as the number of behaviors that were significantly affected by both drugs, divided by the total number of behavioral activities (i.e., 12); Jaccard's coefficient was defined as the number of behaviors that were significantly affected by both drugs, divided by the number of behaviors significantly affected by either drug. Thus, the latter coefficient, unlike the former, excludes negative matches between drugs (i.e., instances in which both drugs fail to significantly affect a particular behavior).

To investigate the replicability of the cluster solution,
Table 1. Definition of behavioral activities recorded observationally during 30-s evaluation periods (adapted from Fray et al. 1980; Iwamoto 1984)

\begin{tabular}{|c|c|}
\hline Activity & Description \\
\hline Loco & Locomotion with all four legs moving \\
\hline Rear & $\begin{array}{l}\text { Rearing, with the head at least } 12 \mathrm{~cm} \text { above the } \\
\text { cage floor }\end{array}$ \\
\hline Sniff & Sniffing for at least $3 \mathrm{~s}$ \\
\hline Lick & Licking cage for at least $3 \mathrm{~s}$ \\
\hline Gnaw & Gnawing on cage for at least $3 \mathrm{~s}$ \\
\hline Groom & $\begin{array}{l}\text { Grooming, with fore paws or hind paws, for at } \\
\text { least } 3 \mathrm{~s}\end{array}$ \\
\hline Head down & Locomotion with nose within $2 \mathrm{~cm}$ of the floor \\
\hline Sway & $\begin{array}{l}\text { Swaying movements of the head (and upper tor- } \\
\text { so) from side to side for at least one complete } \\
\text { cycle (i.e., left-right-left) }\end{array}$ \\
\hline Fall & $\begin{array}{l}\text { Falling from a rearing or standing position back } \\
\text { wards or to the side }\end{array}$ \\
\hline Loss of righting & $\begin{array}{l}\text { Failure to right from a supine position within } \\
15 \mathrm{~s}\end{array}$ \\
\hline Anesthesia & $\begin{array}{l}\text { Loss of righting in combination with absence of } \\
\text { both vocalization and limb withdrawal upon } \\
\text { pinching the toes of the hind paws }\end{array}$ \\
\hline Straub tail & Tail in an erect position \\
\hline
\end{tabular}

the cluster analysis was performed independently on data obtained in group 5, group 8 and in half of the rats of group 11 and of group 12 on the one hand, and in group 6, group 9 and in the remaining rats of group 11 and of group 12 on the other hand, using Gower's similarity coefficient. Because groups 5 and 8 received the drug treatments in an order that was opposite to that used in groups 6 and 9 , this analysis provides information about the replicability of the cluster solution across different treatment orders.

Drugs. The compounds used were d-amphetamine sulfate, apomorphine hydrochloride (Sigma Chemical Co., St. Louis, MO), phencyclidine and ketamine hydrochloride (Warner-Lambert/Parke-Davis and Co., Ann Arbor, MI), DL-2-amino-5-phosphonovalerate hydrochloride (AP5) (Dr. P. Ornstein), pentobarbital sodium (Gaines Chemical Works, New York, NY) and chlordiazepoxide hydrochloride (Hoffmann-La Roche, Nutley, NJ). AP5 was dissolved in a minimum quantity of $1 \mathrm{~N} \mathrm{NaOH}$, to which sterile water was added. All other drugs were dissolved in sterile water. Doses of drugs are expressed in the forms described above.

\section{Results}

Amphetamine, PCP, and pentobarbital produced dose-dependent changes among the various response categories (Fig. 1). Behaviors that were not significantly affected are not shown. Each drug produced a different profile of behavioral activity. Gnawing was induced exclusively by amphetamine; swaying, falling and Straub tail appeared to be characteristic for PCP, and full anesthesia was produced only by pentobarbital. In general, there was close agreement between the assessments of the behaviors that are shown in 
Table 2. Behavioral effects induced by different drug treatments in rats

\begin{tabular}{|c|c|c|c|c|c|c|c|c|c|c|c|c|c|}
\hline & & Loco & Rear & Sniff & Lick & Gnaw & Groom & $\begin{array}{l}\text { Head } \\
\text { down }\end{array}$ & Sway & Fall & $\begin{array}{l}\text { Loss of } \\
\text { righting }\end{array}$ & Anesth. & $\begin{array}{l}\text { Straub } \\
\text { tail }\end{array}$ \\
\hline PCP & $\begin{array}{l}\% \\
\mathrm{D}\end{array}$ & $\frac{100}{3.2}$ & $\begin{array}{l}25 \\
3.2\end{array}$ & $\frac{100}{5.6}$ & $\begin{array}{l}0 \\
-\end{array}$ & $\begin{array}{l}0 \\
-\end{array}$ & $\begin{array}{l}0 \\
-\end{array}$ & $\begin{array}{l}25 \\
5.6\end{array}$ & $\frac{88}{5.6}$ & $\frac{88}{10}$ & $\begin{array}{l}25 \\
32\end{array}$ & $\begin{array}{l}0 \\
-\end{array}$ & $\frac{75}{56}$ \\
\hline PCP ICV & $\begin{array}{l}\% \\
\mathrm{D}\end{array}$ & $\frac{86}{100}$ & $\begin{array}{l}0 \\
-\end{array}$ & $\frac{86}{100}$ & $\begin{array}{l}0 \\
-\end{array}$ & $\begin{array}{l}0 \\
-\end{array}$ & $\begin{array}{l}43 \\
56\end{array}$ & $\frac{57}{100}$ & $\frac{86}{180}$ & $\frac{86}{180}$ & $\begin{array}{l}0 \\
-\end{array}$ & $\begin{array}{l}0 \\
-\end{array}$ & $\frac{43}{3200}$ \\
\hline AP5 ICV & $\begin{array}{l}\% \\
\mathrm{D}\end{array}$ & $\frac{71}{0.32}$ & $\begin{array}{l}29 \\
0.18\end{array}$ & $\frac{71}{0.32}$ & $\begin{array}{l}0 \\
-\end{array}$ & $\begin{array}{l}0 \\
-\end{array}$ & $\begin{array}{l}57 \\
0.32\end{array}$ & $\begin{array}{l}14 \\
0.32\end{array}$ & $\frac{43}{0.32}$ & $\frac{71}{0.56}$ & $\frac{100}{5.6}$ & 0 & $\begin{array}{l}0 \\
-\end{array}$ \\
\hline Amphetamine & $\begin{array}{l}\% \\
\mathrm{D}\end{array}$ & $\frac{100}{3.2}$ & $\frac{100}{3.2}$ & $\frac{100}{1.8}$ & $\begin{array}{l}0 \\
-\end{array}$ & $\frac{88}{10}$ & $\begin{array}{l}0 \\
-\end{array}$ & $\begin{array}{l}25 \\
10\end{array}$ & $\begin{array}{l}13 \\
18\end{array}$ & $\begin{array}{l}0 \\
-\end{array}$ & $\begin{array}{l}0 \\
-\end{array}$ & $\begin{array}{l}0 \\
-\end{array}$ & $\begin{array}{l}0 \\
-\end{array}$ \\
\hline Apomorphine & $\begin{array}{l}\% \\
\mathrm{D}\end{array}$ & $\begin{array}{l}38 \\
0.32\end{array}$ & $\frac{38}{0.32}$ & $\frac{100}{1.0}$ & $\frac{75}{3.2}$ & $\frac{88}{3.2}$ & $\begin{array}{l}13 \\
0.1\end{array}$ & 0 & $\begin{array}{l}0 \\
-\end{array}$ & $\begin{array}{l}0 \\
-\end{array}$ & $\begin{array}{l}0 \\
-\end{array}$ & $\begin{array}{l}0 \\
-\end{array}$ & $\begin{array}{l}0 \\
-\end{array}$ \\
\hline Pentobarbital & $\begin{array}{l}\% \\
\mathrm{D}\end{array}$ & $\begin{array}{l}13 \\
5.6\end{array}$ & $\begin{array}{l}0 \\
-\end{array}$ & $\begin{array}{l}13 \\
5.6\end{array}$ & $\begin{array}{l}0 \\
-\end{array}$ & $\begin{array}{l}0 \\
-\end{array}$ & $\begin{array}{l}0 \\
-\end{array}$ & $\begin{array}{l}13 \\
5.6\end{array}$ & $\begin{array}{l}0 \\
-\end{array}$ & $\begin{array}{l}0 \\
-\end{array}$ & $\frac{100}{56}$ & $\frac{88}{56}$ & $\begin{array}{l}0 \\
-\end{array}$ \\
\hline
\end{tabular}

Behaviors are defined as in Table 1. Drugs are administered IP, unless stated otherwise, using a cumulative dosing procedure. The $\%$ sign indicates the maximum percentage of rats $(n=8$ in tests of IP administered drugs and $n=7$ when drugs are tested ICV) showing a particular behavior; when underlined, this percentage is significantly different from control values $(\alpha=0.05)$. D indicates the lowest dose at which the maximum effect is attained. Doses of AP5 are expressed in $\mu \mathrm{mol} / \mathrm{rat}$ and doses of PCP, when administered ICV, are expressed in $\mu \mathrm{g} / \mathrm{rat}$. All other doses are expressed in $\mathrm{mg} / \mathrm{kg}$

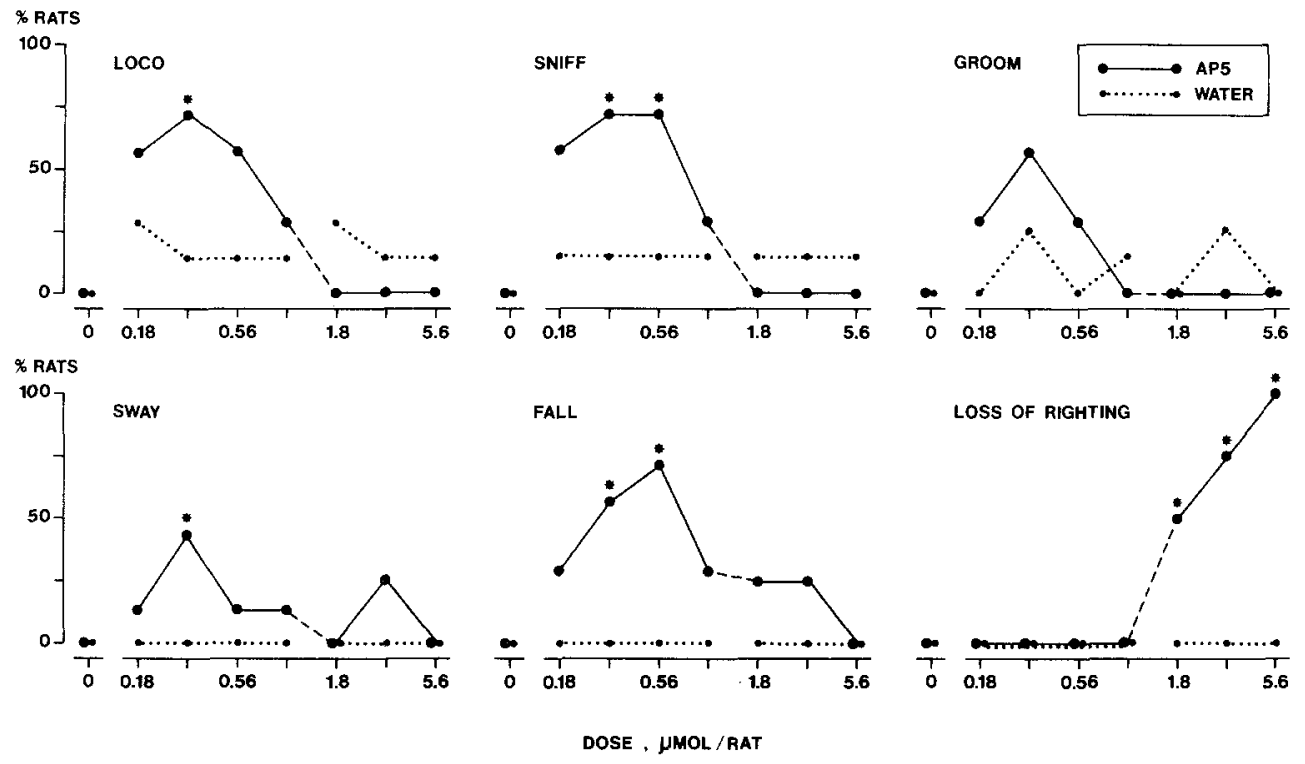

Fig. 2. Behavioral activities induced by ICV administration of cumulative doses of AP5. Ordinates: percentage of rats showing a particular activity; abscissae: cumulative ICV dose administered, in $\mu \mathrm{mol} / \mathrm{rat}$. The injection volume was $5 \mu \mathrm{l} /$ injection. Seven rats were tested with $0.18-1 \mu \mathrm{mol}$ AP5, four rats were tested with $1.8-5.6 \mu \mathrm{mol}$ and seven rats were tested with four ICV injections of sterile water, at 15 -min intervals. Asterisks indicate significant differences at the $5 \%$ level between results obtained after administration of AP5 and of sterile water
Fig. 1 by the two independent observers: the mean value of Cohen's kappa was 0.9 (range $0.6-1.0$ ). The value of kappa was 1.0 for the behaviors not shown in Fig. 1; the observers agreed completely on the absence of these behaviors. Note that none of the responses listed in Table 1 occurred at the beginning of a cumulative dosing session and that their frequency of occurrence during multiple saline sessions was always lower than $25 \%$.

Table 2 summarizes the results obtained during a second series of drug tests, in different rats. Because the results of the subgroups that received drug treatments in different orders were not significantly different $(P>0.05)$, these results were combined. Saline test results, obtained during tests that were interspersed among drug test sessions, were similar to the results of multiple saline injections obtained during the first part of the present study. Thus, the previously obtained saline data served as independent control values in the assessment of the statistical significance of the drug effects observed after IP administration. The results of the repeated ICV injections of sterile water in the drug-treated rats were similar to the data obtained in the rats that were tested with repeated ICV injections of sterile water only. The data obtained in this latter group of rats, shown in Fig. 2, served as independent control values in testing the 
Table 3. Values of Gower's similarity coefficient for quantitative variables that indicate the degree of similarity between the different drug treatments, based on profiles of drug-induced directly observable behavioral effects

\begin{tabular}{llllllll}
\hline & 2 & 3 & 4 & 5 & 6 & 7 & 8 \\
\hline 1 PCP & 0.78 & 0.73 & 0.64 & 0.60 & 0.44 & 0.53 & 0.40 \\
2 PCP ICV & & 0.62 & 0.68 & 0.50 & 0.40 & 0.46 & 0.36 \\
3 Ketamine & & & 0.83 & 0.64 & 0.58 & 0.71 & 0.60 \\
4 AP5 ICV & & & & 0.52 & 0.49 & 0.66 & 0.59 \\
5 Amphetamine & & & & 0.74 & 0.60 & 0.47 \\
6 Apomorphine & & & & & 0.66 & 0.49 \\
7 Chlordiaze- & & & & & & 0.83 \\
$\begin{array}{l}\text { poxide } \\
\text { Pentobarbital }\end{array}$ & & & & & & \\
\hline
\end{tabular}

statistical significance of the effects observed after ICV administration of PCP and of AP5.

AP5 significantly induced locomotion, sniffing, swaying, falling and loss of righting (Fig. 2, Table 2). The maximum drug effect on locomotion, sniffing, and swaying occurred at the same dose; falling was induced at a higher dose and loss of righting at the highest doses tested. The directly observable behavioral effects induced by ICV administration of AP5 appeared to be most similar to the effects of ketamine; the similarity between these drug treatments was larger (Gower's coefficient $=0.83$, matching coefficient $=1.0$, Jaccard's coefficient $=1.0$ ) than the similarity values between the effects of AP5 and any of the other drug treatments. However, the rats that were tested with $1.8-5.6 \mu \mathrm{mol}$ of AP5 died as a result of complications associated with prolonged respiratory depression between 2 and 4 days after the test session. Convulsions were not observed to occur. Systemic administration of AP5 did not produce any of the behavioral activities listed in Table 1, when tested in doses from 10 to $1,000 \mathrm{mg} / \mathrm{kg}$ (results not shown).
PCP induced, at increasing doses, locomotion, sniffing, swaying, falling and Straub tail, in that sequence both after IP and ICV administration (Table 2). Tremors were observed at the highest dose tested. These effects were similar after both routes of administration and were observed at ICV doses of PCP that were about 6-11 times lower than IP doses of PCP.

The matrix displayed in Table 3 was calculated from the data in Table 2 and was used to construct a tree-diagram that described the similarities between the behavioral profiles of the different drug treatments. The highest similarity value in the table is 0.83 , both for ICV administration of AP5 and ketamine and for pentobarbital and chlordiazepoxide. Hence, AP5 was linked to ketamine and pentobarbital was linked to chlordiazepoxide at this similarity level. The similarity of the amalgamation of AP5 and ketamine to the other drug treatments was calculated by averaging the similarities of the other treatments to AP5 and to ketamine (i.e., an average linkage method was used). For example, the similarity of PCP to the new group was calculated as $(0.73+0.64) / 2=0.69$.

Figure 3 shows the tree-diagram that described the results of the cluster analysis. The different drug treatments appeared to be grouped into three main clusters, i.e., stimulant drugs (amphetamine, apomorphine), PCP-like drugs (PCP, ketamine, AP5) and sedative drugs (pentobarbital, chlordiazepoxide). AP5 was grouped in the cluster of PCPlike drugs on the basis of its directly observable behavioral effects when administered ICV. The results obtained when the matching coefficient and Jaccard's coefficient were used as measures of similarity between drug treatments were almost identical to the aformentioned results obtained with Gower's coefficient. The tree-diagrams that were obtained when the data set was divided into two and each half analyzed independently were also very similar to the tree-diagram depicted in Fig. 3. These tree-diagrams are therefore not shown.

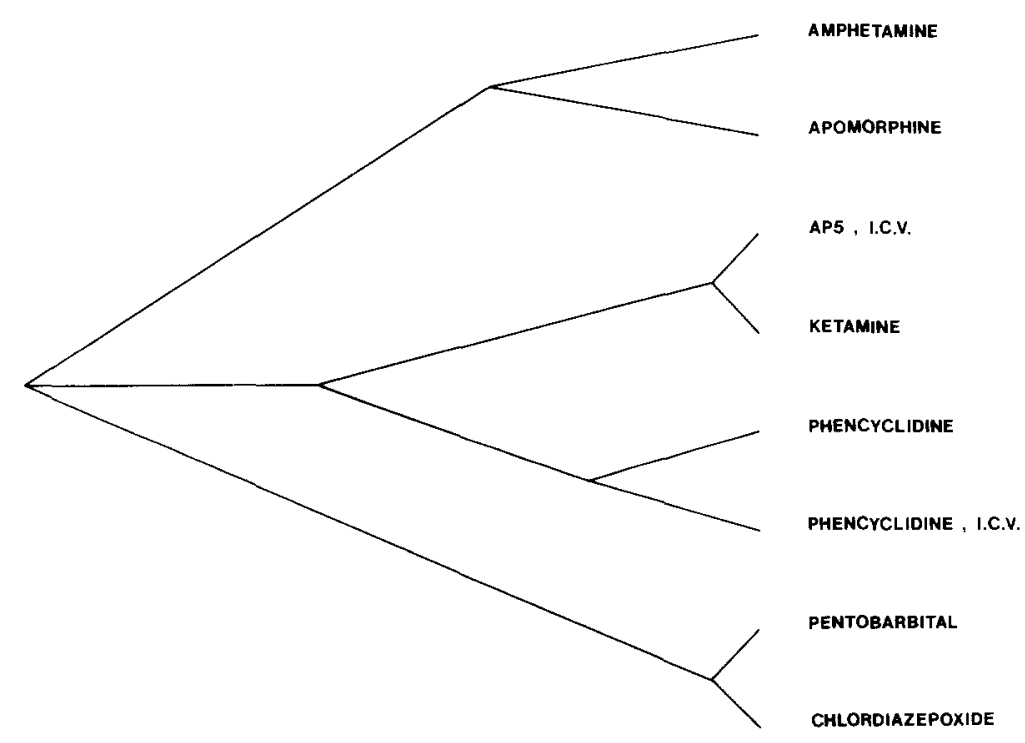

$\begin{array}{cccc}1 & 1 & 1 & 1 \\ 0.55 & 0.65 & 0.75 & 0.85\end{array}$

SIMILARITY
Fig. 3. Tree-diagram describing the similarities between the profiles of directly observable behavioral activity of the drug treatments listed on the right-hand side of the figure. Similarity, shown on the abscissa, was measured using Gower's coefficient for quantitative variables. The treediagram was constructed using hierarchical agglomerative cluster analysis. The drug treatments appeared to cluster into three main groups, i.e., stimulant drugs (amphetamine, apomorphine), phencyclidine-like drugs (phencyclidine, ketamine, AP5) and sedative drugs (pentobarbital, chlordiazepoxide). Note that AP5 was grouped in the cluster of PCP-like drugs 


\section{Discussion}

The first aim of the present study was to characterize the directly observable effects of PCP and of drugs that may produce some, but not all, of these effects, using an adaptation of observational methods (Fray et al. 1980) and a cumulative dosing procedure. The results indicate that the drug-induced changes in behavior can be observed reliably, as evidenced by a close agreement between independent observers, blind to the drug treatment. Further, each of the drugs appeared to produce a specific pattern of behavioral changes. Amphetamine induced locomotion, rearing, sniffing and gnawing, both in the first and in the second experiment. PCP produced locomotion, sniffing, swaying and falling in both experiments. Pentobarbital induced exclusively loss of righting and anesthesia, in both experiments. These results were not significantly different in rats that received the drug treatments in different orders.

In general, the results obtained with amphetamine in the cumulative dosing procedure are in agreement with the amphetamine-induced increase of locomotion, rearing and sniffing reported by Fray et al. (1980) in a single dosing procedure. However, amphetamine was observed to produce gnawing in the present experiment, but not in the study by Fray et al. Other authors (e.g., Schiorring 1971) have reported increases in gnawing by amphetamine, leading Fray et al. to conclude that amphetamine-induced gnawing may depend to a large extent on environmental factors. The results obtained with PCP in the present experiment are in complete agreement with the PCP-induced increases of locomotion, sniffing, swaying and falling, but not of other behaviors, reported by Iwamoto (1984) in a single dosing procedure. PCP was found to be about 6-11 times more potent in inducing directly observable behavioral effects after ICV administration as compared to IP administration. This potency ratio is similar to the recently reported ICV - IP potency ratio for discriminative stimulus effects of PCP in rats (i.e., about 7, studied in a single dosing procedure; Slifer and Balster 1985). In the present study, PCP did not induce full anesthesia, in agreement with observations by Chen (1956) that PCP does induce anesthesia in some species (e.g., rhesus monkey, dog), but not in other species (e.g., rats, mice). Pentobarbital was tested in the present study up to anesthetic doses. Although barbiturates and benzodiazepines are known to produce ataxia, these effects were evidenced only by a complete loss of the righting reflex under the conditions of the present study. The results of the first part of the present study suggest that the adaptation of the method of Fray et al. produces pharmacologically specific results, that can be obtained reliably and rapidly using a cumulative-dosing procedure.

The second part of this study was aimed at evaluating further the hypothesis that behavioral effects of PCP-like drugs may result from reduced neurotransmission at excitatory synapses utilizing NMDA preferring receptors. The drug treatments tested appeared to be grouped, on the basis of their similarities in producing different behavioral activities, into three main clusters, i.e., stimulant drugs (amphetamine, apomorphine), PCP-like drugs (PCP, ketamine, AP5) and sedative drugs (pentobarbital, chlordiazepoxide), irrespective of similarity measure. The cluster solution appeared to have a high degree of replicability, as evidenced by the close agreement between the cluster solutions that were obtained when the data set was divided into two and the cluster analysis was performed independently on both halves. The stimulant drugs characteristically produced sniffing and gnawing; the PCP-like drugs produced locomotion, sniffing, swaying and falling; the sedative drugs produced loss of righting. The behavioral effects produced by the NMDA antagonist AP5 when administered ICV were more similar to the behavioral effects of PCP-like drugs than to the effects of the stimulant and the sedative drugs, supporting the aforementioned hypothesis about the mechanism underlying the behavioral effects of PCP. These results appear to be in agreement with the enhanced locomotion and sniffing produced by AP5 $(1 \mu \mathrm{g})$ when administered in the pars compacta of the substantia nigra and the sedation induced by administration of AP5 in the pars reticulata of the substantia nigra (Dawbarn and Pycock 1981). The results obtained with intracerebral injection of AP5 are suggestive of a possible anatomical dissociation between the stimulating and sedative effects of PCP-like drugs.

Bennett et al. $(1985,1986)$ have reported that the NMDA antagonist 2-amino-7-phosphonoheptanoic acid (AP7), when administered IP in rats, produced anticonflict activity, generalized to diazepam discriminative stimuli, and produced rotorod deficits at 100 and $173 \mathrm{mg} / \mathrm{kg}$. The authors suggest that this diazepam-like profile of action of AP7 may be based on muscle relaxant activity of AP7 that is not mediated by benzodiazepine receptors since the rotorod deficit could not be antagonized by the benzodiazepine antagonist CGS 8216. In the present study no evidence was obtained for behavioral activity of systemically administered AP5, when tested up to a dose of $1,000 \mathrm{mg} / \mathrm{kg}$. The procedure used in the present study was sensitive to the effects of chlordiazepoxide. However, weak muscle relaxant effects of systemic administration of AP5 may not have been observed in the present study because muscle relaxation can be observed only if it is sufficiently severe to result in loss of righting, in the procedure used herein. That NMDA antagonists may produce anti-conflict activity is not inconsistent with a possible PCP-like profile of action of these compounds, as PCP has been reported to possess anti-conflict activity (e.g., Cook and Davidson 1973). Further, ICV administration of AP7 shares discriminative stimulus properties with PCP in rats (Willetts et al. 1986).

A cluster can be described as a group of similar, but not necessarily identical objects. In the present study, different behavioral effects could be observed within clusters of similar drugs. Amphetamine induced locomotion and did not induce licking, unlike apomorphine; chlordiazepoxide did not induce anesthesia, unlike pentobarbital; PCP did not induce loss of righting in all subjects, unlike ketamine. Although the effects of ICV administration of AP5 appeared to be most similar to the effects of ketamine, there was an important difference between these drugs in that AP5 was found to produce loss of righting only when administered in toxic doses. The toxicity did not appear to be an acute effect of AP5 as three out of the four rats tested died 2 or more days after drug administration. In pigeons, ICV administration of AP5 produced PCP-like catalepsy at non-lethal doses (i.e., $1 \mu \mathrm{mol}$; Koek et al. 1986a). Further, in pigeons AP5 produced catalepsy also when administered systemically, at a dose (i.e., $320 \mathrm{mg} / \mathrm{kg}$; Koek et al. 1986b) that was about 700 times higher than the ICV dose. In the present study, AP5 produced an increase in locomotor activity when given ICV in a dose of $0.32 \mu \mathrm{mol} / \mathrm{rat}$ (i.e., $0.075 \mathrm{mg}$ ), but failed to do so upon systemic administration 
of a dose that was about 3,000 times higher. Together, these results suggests that the blood-brain barrier is more permeable to AP5 in pigeons than in rats. In addition, metabolic differences may also underly the differential effects of AP5 in pigeons and in rats. The relatively higher blood-brain barrier to AP5 in rats may be responsible for the delayed toxicity of ICV administration of AP5, as the higher bloodbrain barrier may prolong the time that the drug concentration in the brain remains high, upon which toxicity may occur.

In summary, the directly observable behavioral effects of the NMDA antagonist AP5 in rats appeared to be more similar to the effects of PCP-like drugs (PCP, ketamine) than to the effects of either stimulant drugs (amphetamine, apomorphine) or sedative drugs (chlordiazepoxide, pentobarbital), thus supporting the hypothesis that NMDA antagonism may mediate the effects of $\mathrm{PCP}$, and suggesting the usefulness of the present procedure in classifying PCPlike, stimulant- and sedative drugs. Whether the simple and rapid procedure used in the present study may have a more general applicability in the classification of behaviorally active drugs awaits further study in which other major drug classes (e.g., opiates, neuroleptics, anticholinergics) are included.

Acknowledgements. We thank Richard Castello, Cynthia Schumann and Mel Dickerson for excellent technical assistance and Rebecca McLaughlin for manuscript preparation. This work was supported by a Constantijn and Christiaan Huygens Career Development Award to Wouter Koek (on leave of absence from the Department of Psychophysiology, University of Utrecht, The Netherlands), received from the Netherlands Organization for the Advancement of Pure Research (Z.W.O.), and by U.S. Public Health Service Grant DA-00154

\section{References}

Aldenderfer MS, Blashfield RK (1984) Cluster analysis. Sage university paper series on quantitative applications in the social sciences, 07-044. Sage, Beverly Hills

Bennett DA, Corradi CL, Lehmann J (1985) The excitatory amino acid receptor antagonist, 2-amino-7-phosphonoheptanoic acid (AP7), produces anticonflict activity. Soc Neurosci Abstr 11:106

Bennett DA, Amrick CL (1986) 2-Amino-7-phosphonoheptanoic acid (AP7) produces discriminative stimuli and anticonflict effects similar to diazepam. Life Sci 39:2455-2462

Chen G, Ensor CR, Russell D, Bohner B (1959) The pharmacology of 1-(1-phenylcyclohexyl)piperidine. $\mathrm{HCl}$. J Pharmacol Exp Ther 127:241-250

Cook L, Davidson AB (1973) Effects of behaviorally active drugs in a conflict-punishment procedure in rats. In: Garattini S, Mussini E, Randall LO (eds) The benzodiazepines. Raven, New York, pp 327-345
Dawbarn D, Pycock CJ (1981) Motor effects following application of putative excitatory amino acid antagonists to the region of the mesencephalic dopamine cell bodies in the rat. NaunynSchmiedeberg's Arch Pharmacol 318:100-104

Fray PJ, Sahakian BJ, Robbins TW, Koob GF, Iversen SD (1980) An observational method for quantifying the behavioural effects of dopamine agonists: contrasting effects of $d$-amphetamine and apomorphine. Psychopharmacology 69:253-259

Gordon AD (1981) Classification. Chapman and Hall, New York

Greenberg BD, Segal DS (1986) Evidence for multiple opiate receptor involvement in different phencyclidine-induced unconditioned behaviors in rats. Psychopharmacology 88:44-53

Iwamoto ET (1984) An assessment of the spontaneous activity of rats administered morphine, phencyclidine, or nicotine using automated and observational methods. Psychopharmacology $84: 374-382$

Koek W, Kleer E, Mudar PJ, Woods JH (1986a) Phencyclidine-like catalepsy induced by the excitatory amino acid antagonist DL2-amino-5-phosphonovalerate. Behav Brain Res 19:257-259

Koek W, Woods JH, Ornstein P (1986b) Phencyclidine-like behavioral effects in pigeons induced by systemic administration of the excitatory amino acid antagonist, 2-amino-5-phosphonovalerate. Life Sci 39:973-978

Kullback S (1968) Information theory and statistics. Dover, New York

Leach C (1979) Introduction to statistics. Wiley, New York

Mudar P, Koek W, Jacobson AE, Woods JH (1986) Catalepsy in pigeons induced by excitatory amino acid receptor antagonists. Fed Proc 45:663

Robbins TW (1977) A critique of the methods available for the measurement of spontaneous motor activity. In: Iversen LL, Iversen SD, Snyder SH (eds) Handbook of Psychopharmacology, vol 7. Plenum, New York, pp 37-82

Schiorring E (1971) Amphetamine-induced selective stimulation of certain behaviour items with concurrent inhibition of others in an open-field test with rats. Behaviour 39:1-17

Slifer BL, Balster RL (1985) A comparison of the discriminative stimulus properties of phencyclidine, given intraperitoneally or intraventricularly in rats. Neuropharmacology 24:1175-1179

Sturgeon RD, Fessler RG, Meltzer HY (1979) Behavioral rating scales for assessing phencyclidine-induced locomotor activity, stereotyped behavior and ataxia in rats. Eur $\mathrm{J}$ Pharmacol 59:169-179

Thompson T, Boren JJ (1977) Operant behavioral pharmacology. In: Honig WK, Staddon JER (eds) Handbook of operant behavior. Prentice-Hall, New Jersey, pp 540-569

Watkins JC, Evans RH (1981) Excitatory amino acid transmitters. Annu Rev Pharmacol Toxicol 21:165-204

Willetts J, Chapman MY, Balster RL (1986) Discriminative stimulus effects of 2-amino-7-phosphonoheptanoic acid (APH) in phencyclidine-trained rats. Soc Neurosci Abstr 12:909

Received June 6, 1986/Final version October 10, 1986 